\title{
A EPISTEMologia da CiênCIA da RELIGIÃo: elementos para uma visão deflacionária
}

\author{
EPISTEMOLOGY IN RELIGIOUS STUDIES: \\ elements for a deflationary view
}

Eduardo Rodrigues Cruz*

\begin{abstract}
RESUMO ${ }^{1}$
O objetivo deste modesto ensaio é apresentar alguns desafios para a Ciência da Religião no Brasil, no plano epistemológico, assim como eu os entendo a partir de minha experiência pessoal. Ele leva em conta tanto discussões recentes na área da epistemologia como na da filosofia das ciências naturais, procurando deflacionar o debate sobre a epistemologia. Apresentamos algumas definições e depois aspectos do pensamento de Michael Pye, que defende pluralidade de métodos e objetos, sem que a Ciência da Religião se limite a uma constelação inarticulada de disciplinas mais básicas. Alertamos também para o fato de que a epistemologia de nossa disciplina tem mais em comum com aquela de outras ciências afins do que usualmente admitimos. Destacamos a seguir um aspecto na teoria da ciência, a "epistemologia da virtude", que contempla valores epistêmicos, cognitivos e morais. Apresentamos duas correntes dela: confiabilista (foco no conhecimento) e responsabilista (foco no sujeito). Por fim lançamos uma advertência sobre a confusão entre valores epistêmicos, morais e políticas, quando a militância sobrepuja a preocupação em produzir conhecimento empiricamente validado.
\end{abstract}

Palavras-chave: Epistemologia. Ciência da Religião. Epistemologia da virtude. Michael Pye. Militância.

\begin{abstract}
:
The purpose of this short essay is to present some challenges for the science of religion in Brazil, at the epistemological level, as I understand them from my own experience. It takes into account both recent discussions in the area of epistemology and in the philosophy of the natural sciences, seeking to deflate the debate on epistemology. We present some definitions and then aspects of Michael Pye's thinking, who advocates a plurality of methods and objects, while avoiding the threat of Religious Studies becoming limited to an inarticulate constellation of more basic disciplines. We also point out that the epistemology of our discipline has more in common with that of other related sciences than we usually admit. We highlight here an aspect in the theory of science, the "virtue epistemology," which involves epistemic, cognitive and moral values. We present two currents of this epistemology: reliabilist (focus on knowledge) and responsibilist (focus on the subject). Finally, we caution against the confusion between epistemic, moral, and political values, when partisanship overrides the concern to produce empirically validated knowledge.
\end{abstract}

Keywords: Epistemology. Religious Studies. Virtue epistemology. Michael Pye. Partisanship.

\footnotetext{
* Doutor em Teologia pela Universidade de Chicago. Docente no Programa de Pós-graduação em Ciência da Religião da Pontifícia Universidade Católica de São Paulo. E-mail: erodcruz@pucsp.br

${ }^{1} \mathrm{O}$ presente trabalho representa uma versão ampliada da apresentação feita no V Colóquio Grupo de Pesquisa Religião e Cultura, PUC Minas, em 17 de outubro de 2017. Agradeço aos Profs. Flávio Senra e Fabiano V. Campos pela oportunidade e pelas frutuosas discussões.
} 
A palavra "epistemologia" exerce certo fascínio em nossas mentes, assim como os termos "quântico", "complexo" e outros pertencentes aos modismos na academia. Parece que, pelo simples fato de utilizá-los, subimos um degrau na sofisticação de nosso discurso. Discursos sofisticados, no entanto, podem ser como o mágico de $\mathrm{Oz}$, que se esconde por detrás da cortina e de fato é pouco mais que um homenzinho. Nossa intenção nesse breve texto é indicar algumas formas de deflacionar a discussão epistemológica no seio da Ciência da Religião, aproximando-a do bom senso e de cânones mais bem estabelecidos na epistemologia e na filosofia da ciência.

Comecemos pela noção de Epistemologia. Para que tenhamos uma ideia melhor do que ela trata, vamos recorrer a uma fonte abalizada, a The Stanford Encyclopedia of Philosophy. De acordo com o verbete de Matthias Steup (2017), a epistemologia, definida de modo estrito, nada mais é que o estudo do conhecimento e da crença justificada. Para a questão do conhecimento, ela se preocupa com questões tais como: Quais são as condições necessárias e suficientes do conhecimento? Quais são suas fontes? Qual é sua estrutura e quais são seus limites? Já para o caso da justificação, a epistemologia tem diante de si questões como: Como devemos entender o conceito de justificação? O que faz as crenças serem de fato justificadas? Será tal justificação interna ou externa à mente humana?

Como se sabe, considerações epistemológicas nos vêm desde os antigos filósofos gregos, e com isso possuem uma longa trajetória no pensamento ocidental, com influências medievais, do cartesianismo e do empirismo newtoniano. Grosso modo, as concepções a seu respeito podem agora ser divididas em dois momentos, antes e depois dos anos 50 do século passado. As teorias do conhecimento tradicionais, mesmo nas discussões analíticas que encontramos no bojo do positivismo lógico, constituem-se como "teorias de conhecimento como produto", ao passo que as teorias de investigação epistemológica atuais se constituem mais como "teorias do conhecimento como processo" (DUTRA, 2010, p. 12). Essa transição é importante para a reflexão sobre a epistemologia da virtude, que será vista abaixo.

Esse novo giro para a prática aproxima a epistemologia do conhecimento dito científico, atentando-se agora para a história das disciplinas e para suas práticas específicas. Passa-se assim a desenvolver uma Filosofia da Ciência (ou Teoria da Ciência) com dimensões históricas e sociológicas. Para se melhor conceber o que está em jogo na disciplina geral e nas suas especificações, pode-se recorrer a duas obras de 
Luiz Henrique Dutra, Introdução à Epistemologia (DUTRA, 2010) e Introdução à Teoria da Ciência (DUTRA, 2009). Na primeira obra, são abordados temas tais como a noção de crença verdadeira e justificada, contraste realidade-ilusão, racionalismo e empirismo, a possibilidade da metafísica, e formas normativas (as propostas do positivismo nos séculos XIX e XX) e descritivas (a Epistemologia Naturalizada) da Epistemologia. Já a segunda obra trata dos modos de confirmação das asserções científicas, teorias do progresso científico, aceitação de teorias, entendimento de explicação e uso de modelos.

Tais abordagens desenvolveram-se a partir de questões de perguntas e práticas advindas do contexto das ciências naturais. Defendo aqui que, ao invés de se opor ciências humanas e ciências naturais, procuremos estar mais atentos às lições que a filosofia da ciência advinda dessas últimas tem a nos dar. Já vários estudiosos da Ciência da Religião (CRE) têm-se dedicado à tarefa de aprofundar questões de, como se convencionou a denominar, método e teoria (p. ex., JENSEN, 2013). Há questões específicas que são mais bem tratadas quando nos referimos à filosofia da ciência, como por exemplo a questão de pluralismo de método e objeto.

Seguindo um experiente comparativista, Michael Pye, pode-se defender que "A Ciência da Religião deve ser vista como uma 'disciplina'. O que é uma disciplina no sentido científico? É nada mais que uma abordagem sistematicamente ordenada [método] para o estudo de um campo [objeto]” (PYE, 2017, p. 162). Ele acrescenta que isso "não implica que a Ciência da Religião tenha um método especial, único a ela. A disciplina da Ciência da Religião exige, pois, um agrupamento de métodos. A disciplina resultante não é exatamente a mesma que as disciplinas necessárias para o estudo de outros campos, ou campos definidos de maneira diferente”. (Ibid., 163). Como então articular tal pluralidade?

Ainda segundo Pye, pode-se apontar três focos para a articulação das subdisciplinas na CRE: O primeiro foco diz respeito aos aspectos a que devem ser levados em conta quanto ao campo disciplinar: o comportamental (práticas dos fiéis, empiricamente acessíveis), o conceitual, o subjetivo (autodescrição da experiência do fiel) e o social (Ibid., 168ss). Todos esses quatro aspectos elementares deveriam ser considerados em sua relação integral, um com o outro. Respondendo ao anseio de muitos de levar a experiência religiosa a sério, um objeto com múltiplos aspectos deveria ser estudado, em primeira instância, em termos de seu significado integral 
para os crentes e participantes em questão (o que Pye chama de processo de "reconhecimento" [Ibid., 171]). Depois, deve-se dar a devida atenção para a potencial emergência de questões ou insights que entram em tensão, ou atravessam, a autocompreensão dos crentes ou participantes (Ibid., 172). Essa tensão se deve a três fatores: a) uma estrutura pode se manifestar, mas não ser aparente, ou ser parcialmente aparente, para os crentes ou participantes em questão - a percepção do pesquisador pode estar mais "correta" do que a do fiel; b) a perspectiva teórica resultante do conhecimento comparativo pode não ser visível aos crentes e participantes; c) as tensões indicadas requerem explicações no sentido mais forte da palavra.

O segundo foco leva em conta as fontes para o trabalho acadêmico, escritas, orais ou materiais (Ibid., 173-175), que exigem para seu tratamento um conhecimento linguístico adequado, além de trabalho de campo, mas lembrando que os participantes/crentes frequentemente não estão disponíveis para tal trabalho (p. ex., no caso de religiões do passado). O terceiro foco diz respeito à distinção entre Teoria e Método (Ibid., 175-76). O trabalho de comparação e contextualização deve levar a categorias, tipologias e teorias. A comparação é necessária nas fases de reconhecimento e explanatória para o estudo da religião. A contextualização significa considerar um ou mais aspectos de um caso da religião no seu contexto histórico, sociocultural ou até mesmo biológico.

Como adverte o autor, é fácil dizer que a Ciência da Religião é “interdisciplinar”, e isso pode parecer útil em um primeiro momento. Com frequência a ênfase na “interdisciplinaridade" parece sugerir abertura a uma variedade de métodos quando, na verdade, esquiva-se do desafio de uma reflexão metodológica (Ibid., 177)².

Uma análise do trabalho de Pye e outros autores contemporâneos sugere que não há receitas prontas para o desenvolvimento da Ciência da Religião. Os conflitos e tensões são, em maior ou menor escala, semelhantes aos encontrados no estudo de outros objetos escolhidos pelas ciências humanas, e muitas vezes o elemento de distinção diz mais respeito à história pregressa da nossa disciplina. Talvez seja o caso de, ao invés de buscar uma hipotética epistemologia própria dessa ciência, atentarmos mais para as virtudes que o pesquisador deve assumir, como acadêmico e

2 Isso supõe, é claro, certo entendimento por parte de Pye sobre o significado de "interdisciplinaridade", mas não podemos perder outros de vista. 
como sujeito epistêmico, para produzir uma ciência autenticamente empírica e confiável.

Gostaríamos assim de dar ênfase a um aspecto na teoria da ciência, aquele que diz respeito a valores e virtudes necessários para o bom desenvolvimento de qualquer uma delas. Já na década de quarenta do século passado, o sociólogo Robert King Merton elencou quatro valores (normas) ideais, constitutivos e exemplares da ciência, a saber: 1) Universalismo - significa que todos os cientistas podem contribuir para a ciência, independentemente de raça, nacionalidade, cultura ou gênero. 2) "Comunismo" - implica que os resultados científicos são propriedade comum de toda a sociedade. 3) Desinteresse - considera que os cientistas devem agir em busca dos interesses coletivos do empreendimento científico, que estão acima de seus interesses pessoais. 4) Ceticismo organizado - ceticismo determina que alegações científicas devem ser expostas a uma análise crítica antes de serem aceitas (MERTON, 2013 [1942]). Pode-se também acrescentar a originalidade, a exigência que as atividades científicas contribuam com novidades, seja um novo problema, uma nova abordagem, novos dados, uma nova teoria ou explicação.

Mais recentemente, têm-se desenvolvido a "Epistemologia da Virtude"3, de cunho mais marcadamente normativo. Seguiremos aqui um interessante esquema proposto pelo filósofo da ciência Lorenzo Casini (2010). Em primeiro lugar ele se pergunta de que formas os valores, de forma mais geral, podem contribuir para a ciência, utilizando-se a sequência temporal da prática científica: em seus estágios iniciais, ou seja, no planejamento e na condução da pesquisa; nos padrões de aceitação para pretensões de conhecimento; nos efeitos que a ciência possa vir a ter. Ainda que a epistemologia da virtude tenha sido objeto de estudo para vários acadêmicos brasileiros, parece não haver nada na área de Ciência da Religião.

Três são os tipos de valor que são considerados nesses estudos: os Epistêmicos, aqueles que conduzem à verdade4; os "Cognitivos", que dizem respeito a características outras que a verdade, que se queira de um resultado ou prática

3 Tradução reconhecidamente insuficiente de Virtue Epistemology. Trata-se mais precisamente da teoria do conhecimento que procura analisar as virtudes epistêmicas necessárias para o trabalho científico. Para o uso dessa tradução, ver Müller e Luz (2015).

4 Essa palavra se transformou na Bête Noire da Epistemologia contemporânea, havendo uma forte suspeita da afirmação tradicional que a ciência é a busca da verdade. Adotamos aqui, entretanto, a posição de que a teoria da correspondência da verdade continua sendo o modo default da Epistemologia, mas deve ser confrontada com outras teorias, como da coerência, a pragmática e a do consenso. 
científica: simplicidade intersubjetivamente aquiescida, fertilidade, mutualidade de interação, parcimônia ontológica (navalha de Ockham), heterogeneidade ontológica, etc. E, finalmente, os "Morais", como os bem-conhecidos no plano da ética, política e economia.

Por que se dar destaque aos valores, se em uma primeira avaliação eles deveriam ficar mais no domínio da ética? Em uma era pós-positivista, sabemos que as afirmações científicas vão além daquilo que já está estabelecido empiricamente. Temos, por exemplo, o problema da subdeterminação, ou seja, os dados conhecidos sempre subdeterminam a hipótese, ou, em outras palavras, sempre haverá mais do que uma hipótese compatível com tais dados. Por conta disso, valores como os epistêmicos podem ajudar na aferição das afirmações científicas. A seguinte lista de valores pode ser apresentada, que suplementa e corrobora as listas acima, ainda que seja certamente sujeita a disputas, a saber: Acurácia (adequação empírica), consistência interna e externa, amplitude de escopo, simplicidade, fertilidade, poder de unificação, poder de explicar os fatos conhecidos e diferentes tipos de fato, falseabilidade, responder porque as explicações rivais não são bem sucedidas, capturar as rivais como casos-limites, originalidade, heterogeneidade ontológica, mutualidade de interação, aplicabilidade às necessidades humanas (pragmático), difusão de poder (pragmático). Nenhum desses valores são propriamente morais.

Sigo agora Jason Baher (2004) para uma posterior discriminação. Há duas correntes principais para a epistemologia da virtude: a confiabilista e a responsabilista. Os adeptos da primeira se perguntam quão confiável é o conhecimento produzido, relativamente aos padrões de verdade, e procuram fornecer análises do conhecimento e/ou justificações epistêmicas com base em virtudes. Alguns epistemólogos, como Ernesto Sosa (1986), definem uma virtude intelectual como "qualquer característica de uma pessoa que seja estável e conducente à verdade” (Ibid.). Tais virtudes podem estar relacionadas a certas faculdades cognitivas como a visão, a memória e a introspecção, pois elas de modo geral são compatíveis com a condução à verdade. Estes epistemólogos tendem a se interessar na formulação de descrições baseadas em virtudes da justificação ou do conhecimento. Vários argumentaram, por exemplo, que o conhecimento deve ser entendido grosso modo como crença verdadeira que surge de um exercício de virtude intelectual. Um segundo grupo de epistemólogos, que inclui Linda Zagzebski (2009) 
e Lorraine Code (2011 [1981]), concebem as virtudes intelectuais como bons traços de caráter do pesquisador. Exemplos podem incluir uma mente aberta, envergadura intelectual, imparcialidade e equilíbrio, e espírito inquisitivo. Os traços que esses epistemólogos consideram como virtudes intelectuais podem ser também vistos como os traços de um conhecedor responsável, daí o rótulo de responsabilismo. Essa taxonomia gerou críticas, pois não é claro porque se deve escolher uma abordagem sobre a outra, mas nosso propósito aqui é simplesmente descritivo.

Dessa forma, é preciso estar alerta aos problemas associados com tais valores epistêmicos, a começar por quem decide quais são eles. Depois, eles são muito vagos para fornecer respostas apropriadas, e com frequência conflitam entre sí5 e não há uma ordem natural deles. Em seguida, o que leva a crer que eles são epistêmicos, e porque privilegiá-los se não podemos mostrar que eles de fato são epistêmicos?

A despeito disso, o que devemos ter em mente é que a ciência é um trabalho coletivo, como já indicado pelos valores mertonianos. Ela envolve um debate intersubjetivo crítico, reflexivo, bem informado e balizado por valores, o que permite a clarificação desses problemas e a minimização deles.

Por fim, e com mais força no caso das ciências humanas, pode-se perguntar sobre o papel de nossos valores morais para se chegar a um acordo sobre o que pensamos ser a verdade. Fiar-se pelo exercício desses valores (os morais) não necessariamente deve ser a melhor estratégia epistemológica, ainda que muitos possam pensar que deva ser assim. Veja-se o caso, por exemplo, do aspecto "militante" das ciências, ou seja, o fato de que as pesquisas que desenvolvemos refletirem claramente interesses sócio-políticos, reforçando o engajamento do pesquisador em uma causa.

Independentemente da justeza de tal causa, e sem se advogar uma impossível neutralidade, o âmbito da política e seu jogo de interesses e poder não é o mesmo que o da ética, que por sua vez não o mesmo que da epistemologia. Além disso, abordagens militantes tendem a desconsiderar formas tradicionais de se buscar a verdade enquanto se refiram a uma realidade externa à mente e à práxis humana. Surgem daí algumas epistemologias alternativas, como a feminista, a pós-colonialista (ver propostas a respeito em Wirth [2013, p. 139-41]), “do Sul”, etc., todas de cunho

\footnotetext{
5 O próprio Merton reconhece a existência de contra normas na atividade científica, conduzindo a uma
} ambivalência na ciência (MERTON, 1979). Entretanto, isso não exclui a proeminência das normas. 
relativista. A despeito da eventual qualidade e oportunidade de tais abordagens, talvez haja aí um mal-entendido. A justeza das causas defendidas pode passar a obscurecer alguns elementos básicos do conhecimento humano, o primeiro deles referindo-se às formas comuns de pensar derivadas de sermos uma única espécie biológica.

A epistemologia, atuando criticamente desde o tempo dos gregos, consolidou uma imagem da forma como o ser humano se lança à tarefa de buscar conhecimento. Mesmo admitindo-se o caráter eurocêntrico e cristianocêntrico de formas contingentes da epistemologia, podemos voltar às virtudes epistêmicas como base comum entre os vários grupos de interesse na academia, acentuando, por exemplo, a falseabilidade e a honestidade intelectual do pesquisador. Assim evita-se o primado da política na produção do conhecimento e resgata-se a importância da teoria da correspondência da verdade.

\section{REFERÊNCIAS}

BAHER, Jason S. Virtue Epistemology. 2004. Disponível em: <http://www.iep.utm.edu/virtueep/>. Acesso em: 15 abr. 2018.

CASINI, Lorenzo. Value Freedom: Is it Possible. Is it Desirable. 2010; Disponível em: <http://philosophy.ucsd.edu/_files/ncartwright/phil152/week4-phil152.ppt>. Acesso em: 1 dez. 2017.

CODE, Lorraine. Responsabilismo. In: FERNÁNDEZ, Miguel Ángel; VALDÉS, Margarita M (Org.) Normas, virtudes y valores epistémicos: Ensayos de epistemología contemporânea. Ciudad de Mexico: Instituto de Investigaciones Filosóficas, 2011 [1981]. p. 279-98.

DUTRA, Luiz Henrique de Araújo. Introdução à Teoria da Ciência. $3^{\mathrm{a}}$. ed. Florianópolis: Ed. da UFSC, 2009.

DUTRA, Luiz Henrique de Araújo. Introdução à Epistemologia. São Paulo: Ed. UNESP, 2010.

JENSEN, Jeppe S. Epistemologia. Rever - Revista de Estudos da Religião, ano 13, n. 02, jul./dez. 2013, p. 171-191.

MERTON, Robert K. A Ciência e a Estrutura Social Democrática [1942]. In: MERTON, Robert K. Ensaios de Sociologia da Ciência. São Paulo: Associação Filosófica Scientiae Studia Editora 34, 2013. p. 181-198.

MERTON, Robert K. Ambivalência Sociológica e Outros Ensaios. Rio Janeiro: Ed. Zahar, 1979. 
MÜLLER, Felipe de Matos; LUZ, Alexandre Meyer (Org.). O que nós conhecemos: Ensaios em epistemologia individual e social. Porto Alegre: EDIPUCRS / Editora Fi, 2015.

PYE, Michael Pye, Integração metodológica na Ciência da Religião. Rever - Revista de Estudos da Religião, ano 17, n. 2, mai./ago. 2017, p. 162-178.

SOSA, Ernesto. Faces e Destinos da Epistemologia. Ciência e Filosofia USP, n. 3, 1986. p. 181-206.

STEUP, Matthias. Epistemology. In: The Stanford Encyclopedia of Philosophy (Fall 2017 Edition), Edward N. ZALTA (Org.). Disponível em:

<https://plato.stanford.edu/archives/fall2017/entries/epistemology/>. Acesso em: 15 dez. 2017.

WIRTH, Lauri. Religião e Epistemologias Pós-Coloniais. In: PASSOS, J.D.; USARSKI, Frank (Org.). Compêndio de Ciência da Religião. São Paulo: Paulus; Paulinas, 2013. p. 129-142.

ZAGZEBSKI, Linda. Confianza epistémica y conflicto epistémico. Diánoia, v. LIV, n. 62 (may 2009), p. 27-45. 